\title{
COLECISTITIS ACALCULOSA SECUNDARIA A INFECCIÓN POR VIRUS DE LA HEPATITIS A*
}

\author{
Drs. Karla Lisseth Leonher R. ${ }^{1}$, Miguel Fuentes M. ${ }^{2}$, Karina de Haro C. ${ }^{2}$, \\ Celina Margarita Hernández R. ${ }^{2}$, José López Z. ${ }^{1}$, José Alfredo Jiménez G. ${ }^{1}$ \\ 1 Unidad de Cirugía Digestiva y Hepatobiliar. Novam\&Vita. \\ 2 Unidad de Medicina Interna. U-MET. \\ Guadalajara, Jalisco, México.
}

Abstract

\section{Acute acalculous cholecystitis secondary to viral hepatitis A}

Introduction: The hepatitis A (HAV) is usually limited and common disease in children; very little is known about acalculous cholecystitis secondary to hepatitis because there are few reports worldwide. Case report: We report the case of a woman of 33 years who began with diarrhea, fever, jaundice and right upper quadrant pain, laboratory HAV IgM positive. No improvement of pain to medical treatment, we request an ultrasound and cholangioresonance identifying signs of cholecystitis and edema of the wall; we performed laparoscopic cholecystectomy with symptom improvement. Secondary VHA cholecystitis is a rare entity, a medical or surgical treatment according to the patient's clinical is needed to avoid complications.

Key words: Hepatitis A, jaundice, cholecystitis, laparoscopic cholecystectomy.

\section{Resumen}

Introducción: El virus de la hepatitis A (VHA) es por lo general una enfermedad limitada y frecuente en niños; se conoce muy poco sobre la colecistitis acalculosa secundaria a hepatitis ya que existen pocos reportes a nivel mundial. Caso clínico: Presentamos el caso de una mujer de 33 años la cual inició con diarrea, fiebre, ictericia y dolor en hipocondrio derecho, laboratorio con IgM positivo a VHA. Sin mejoría del dolor a tratamiento médico, solicitamos un ultrasonido y colangioresonancia identificando datos de colecistitis y edema de pared; sometiéndola a colecistectomía con mejoría de los síntomas. La colecistitis secundaria a VHA es una entidad poco frecuente, es necesario un tratamiento médico o quirúrgico de acuerdo a la clínica del paciente para evitar complicaciones.

Palabras clave: Hepatitis A, ictericia, colecistitis, colecistectomía laparoscópica.

*Recibido el 11 de mayo de 2015 y aceptado para publicación el 2 de septiembre de 2015.

Los autores no refieren conflictos de interés.

No se tuvo apoyo financiero.

Correspondencia: Dra. Karla Leonher R. karlaleonher@gmail.com 


\section{Introducción}

La infección del virus de la hepatitis A (VHA) es una enfermedad auto limitada usualmente asintomática que ocurre principalmente en niños, frecuente en países en vías de desarrollo. Por lo general se limita únicamente al hígado y con un período de recuperación que oscila de 2 a 3 semanas; sin embargo, pueden presentarse complicaciones como colecistitis acalculosa, ascitis, efusión pleural, hepatitis fulminante o desencadenar enfermedades autoinmunes extra hepáticas. Dentro de las principales alteraciones en los exámenes de laboratorio están leucopenia, linfocitosis, alteración en las pruebas de función hepática y serologías IgM positivas para hepatitis, la trombocitopenia por sí misma es un marcador de la severidad de la enfermedad.

La colecistitis aguda acalculosa es una complicación rara de la hepatitis viral aguda, sin embargo, no existe un etiopatogenia bien establecida; únicamente se conoce la afinidad del VHA por el epitelio de la vesícula y de la vía biliar así como la respuesta inmunológica sobre el epitelio vesicular con una infección del VHA.

Se presenta el caso de una paciente de 33 años, la cual inicia con diarrea, deshidratación e intolerancia a la vía oral, siendo tratada con manejo médico conservador sin respuesta; 3 días después se agrega ictericia, solicitamos serologías para VHA siendo positivas y un ultrasonido de hígado y vías biliares encontrando una vesícula con lodo biliar y pared engrosada de $6 \mathrm{~mm}$; continuamos con manejo médico a base de reposo, hidratación y analgésicos antiinflamatorios, los síntomas se intensifican con menor tolerancia a la vía oral y dolor importante en el hipocondrio derecho por lo que se decide su hospitalización 5 días después de iniciado el cuadro para hidratación parenteral y analgesia a base de ketorolaco. A su ingreso con ictericia, en mal estado de hidratación, siatema cardiorrespiratorio sin alteraciones, abdomen blando, depresible, con dolor a la palpación profunda en epigastrio, Murphy positivo, hígado palpable $3 \mathrm{~cm}$ por debajo del reborde costal, peristalsis presente, resto sin alteraciones. Se toma nuevo ultrasonido de hígado y vías biliares de control reportando hepatomegalia difusa, litiasis vesicular y engrosamiento de la pared de $13 \mathrm{~mm}$, con edema peri vesicular (Figura 1).

Se toman exámenes de laboratorio a su ingreso con leucocitos $9.800, \mathrm{Hb} 13,8 \mathrm{mg} / \mathrm{dL}$, plaquetas $280 \mathrm{mil} / \mathrm{L}$, bilirrubina total $3,53 \mathrm{mg} / \mathrm{dL}$, bilirrubina directa $2,34 \mathrm{mg} / \mathrm{dL}$ e indirecta de $1,56 \mathrm{mg} / \mathrm{dL}$, gama glutamil transferasa $210 \mathrm{U} / \mathrm{L}$, fosfatasa alcalina 410 U/L, TGO $770 \mathrm{U} / \mathrm{L}$, TGP $1.735 \mathrm{U} / \mathrm{L}$.

Continúa manejo conservador y antiinflamatorio sin respuesta al mismo, persistiendo con vómitos $\mathrm{y}$ dolor importante a la palpación en hipocondrio derecho; 8 días después se toman estudios de control encontrando elevación de las bilirrubinas totales $6,3 \mathrm{mg} / \mathrm{dL}$, directa $3,80 \mathrm{mg} / \mathrm{dL}$, indirecta $2,50 \mathrm{mg} /$ $\mathrm{dL}$, gama glutamil transferasa $286 \mathrm{U} / \mathrm{L}$, fosfatasa alcalina $610 \mathrm{U} / \mathrm{L}, \mathrm{TGO} 263 \mathrm{U} / \mathrm{L}$, TGP $862 \mathrm{U} / \mathrm{L}$; ante la falta de respuesta a tratamiento se toma una colangioresonancia en donde se evidencia persistencia de la inflamación vesicular después de 11 días de iniciado el cuadro y se corrobora permeabilidad de la vía biliar extra hepática (Figura 2).

Se decide someter a la paciente a una colecistectomía laparoscópica a falta de respuesta a manejo médico, se encuentra edema e inflamación importan-

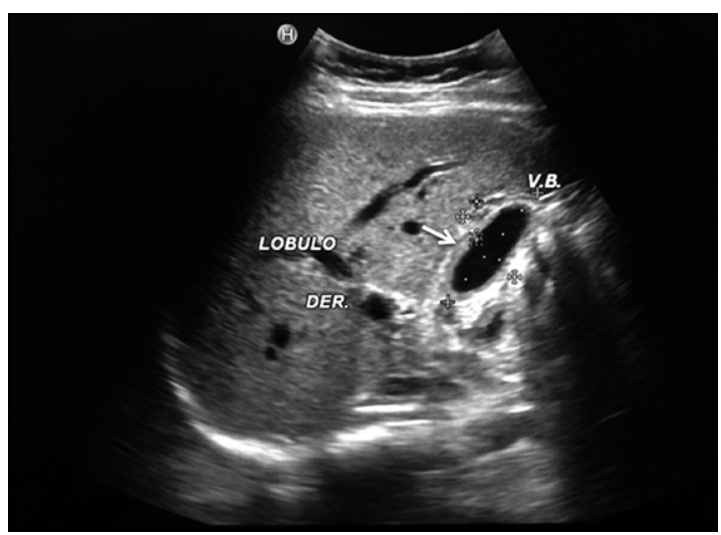

Figura 1. Ultrasonograma de Hígado y Vías Biliares. Se aprecia engrosamiento de la pared vesicular por edema (Flecha).

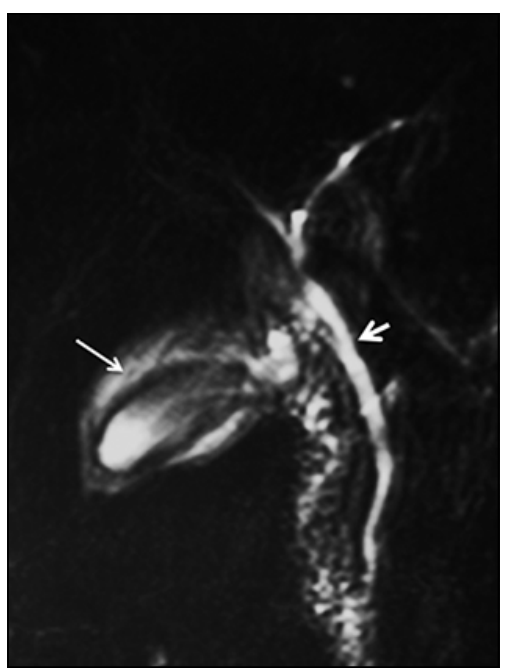

Figura 2. Colangioresonancia donde se observa engrosamiento de la pared (Flecha delgada) sin evidencia de dilatación de la vía biliar (Flecha gruesa). 


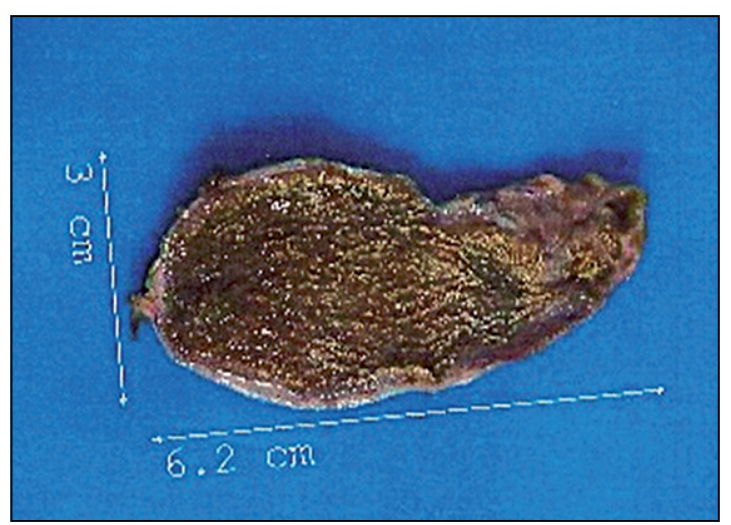

Figura 3. Histopatológico pieza macroscópica.

te de la vesícula importante, realizando el procedimiento sin complicaciones. Posterior a la cirugía la paciente tuvo mejoría del dolor, náuseas/vómitos y con adecuada tolerancia a la dieta, posterior a esto se mantuvo con adecuada evolución. La histopatología confirma una vesícula edematosa y congestiva con infiltrado inflamatorio de tipo mixto con predominio de polimorfos nucleares que afecta hasta la capa muscular, negativo a malignidad (Figura 3 ).

\section{Discusión}

Hay pocos reportes referentes al tema ${ }^{1-9}$. Las infecciones por virus de la hepatitis A en la mayoría de los casos son asintomáticos, iniciando abruptamente con náusea, vómito, diarrea, fiebre, ictericia, astenia, disminución del apetito y distensión abdominal; en promedio la recuperación se alcanza en 2 a 3 semanas sin llevar alguna complicación. Dentro de las principales alteraciones de laboratorio incluyen leucopenia, linfocitosis, alteración de las pruebas de función hepática y serología IgM positivas. En un estudio de Kim et al. ${ }^{10}$, se encontró que los pacientes con trombocitopenia tienen un retardo en su recuperación pero también son más propensos a complicaciones, sin encontrar este hallazgo en nuestro caso.

Las colecistitis acalculosas representan un pequeño porcentaje, la mayoría de estas se deben a un proceso infeccioso que afecta la pared de la vesícula siendo el agente más común relacionado la Salmonella typhii; otras causas son las vasculitis sistémicas, infecciones por estreptococos, pacientes quemados, en ayuno prolongado y con nutrición parenteral total.

Por lo general, el diagnóstico de la colecistitis acalculosa se sospecha por clínica pero se confirma por ultrasonido, dentro de los requisitos se encuentra distensión de la vesícula, engrosamiento de la pared vesicular mayor a $3,5 \mathrm{~mm}$, no proyecta sombra acústica y edema peri vesicular, mismos datos que fueron encontrados en nuestra paciente.

Hay muy pocos reportes sobre la relación del virus de la hepatitis A y la colecistitis acalculosa, se ha encontrado que la mayoría de las veces el manejo conservador es suficiente para controlar la colecistitis, sin embargo, hay 4 reportes de 20 documentados en la literatura que requirieron manejo quirúrgico para mejorar los síntomas o incluso prevenir una complicación mayor como el caso reportado por Black y cols. ${ }^{11}$, en donde la colecistitis se acompañaba de necrosis de la pared vesicular.

Existe un reporte de Mourani y cols. ${ }^{12}$, en donde se realizó inmunohistoquímica a la vesícula extirpada encontrando que el virus de la hepatitis A afecta directamente la pared de la vesícula biliar y los conductos, encontrando inflamación portal, peri colangitis y colestasis en el hígado así como colecistitis linfocítica; en los hepatocitos se demostraron anticuerpos de la hepatitis A en su citoplasma y también en el epitelio de la vía biliar intrahepática y la vesícula biliar. Esto explica el por qué la infección del VHA puede causar colecistitis, colestasis y excreción del virus por las heces perpetuando su ciclo de infección oral-fecal.

La relevancia de este caso radica en la baja incidencia de la relación de infección por VHA y colecistitis y la poca información en la literatura respecto al tratamiento. En el caso de nuestro paciente, a pesar de ser manejado de forma conservadora, no hubo mejoría de los síntomas ni mejoría en la inflamación vesicular, siendo la cirugía un factor determinante para su recuperación, este reporte se encuentra entre los pocos descritos en la literatura que mejora con manejo quirúrgico; una infección por el VHA puede ocasionar una colecistitis acalculosa aguda, que puede requerir de una intervención quirúrgica.

\section{Conclusiones}

La colecistitis aguda acalculosa es una complicación rara de la hepatitis $\mathrm{A}$, existen pocos reportes sobre ella y su tratamiento inicial es médico, aun cuando en ocasiones puede requerir colecistectomía.

\section{Referencias}

1. Melero Ferrer JL, Ortuño Cortés J, Nevárez Heredia A, Yago Baenas M, Berenguer M. Colecistitis aguda acalculosa asociada a infección aguda por el virus de la hepatitis A. Gastroenterol Hepatol. 2008;31:433-5.

2. Hermier M, Descos B, Collet JP, Phillibert M, Poui- 
llaude JP, Pacros. Acute cholecystitis disclosing A virus hepatitis. Arch Fr Pediatr. 1985;42:525-9.

3. Safak K, Eskazan AE, Ay N, Baysal B, Bahadir B, Bahadir MV, Onur A, et al. Acute acalculous Cholecystitis due to Viral Hepatitis A, Case Rep Infect Dis; 2013;407.

4. Ozaras R, Mert A, Yilmaz MH, Celik AD, Tabak F, Bilir $\mathrm{M}$, et al. Acute viral cholecystitis due to hepatitis A virus infection. J Clin Gastroenterol 2003;37(1):79-81.

5. Saxena SK. Acute viral cholecystitis in viral hepatitis. J Assoc Physicians India 1994;42(5):428.

6. Basar O, Kisacik B, Bozdogan E, Yolku OF, Ertugrul I, Koklu S. An unusual cause of acalculous cholecystitis during pregnancy: hepatitis A virus. Dig Dis Sci 2005;50(5):1532.

7. Casha P, Rifflet H, Renou C, Bulgare JC, Fleschi JB. Acalculous acute cholecystitis and viral hepatitis A. Gastroenterol Clin Biol 2000;24(5):591-2.
8. Dalgiç N, Ince E, Öncel S, Günes M. Acute viral acalculous cholecystitis due to viral hepatitis A. Dahili Bilimler Medical Sciences 2005;58:78-80.

9. Herek Ö, Çördük N, Herek D, Bagci S. Acute acalculous cholecystitis due to hepatitis A infection in a child: A rare cause of acute abdomen. Ann Afr Med 2011;10:193-5.

10. Kim HS, Kim HS, Lee JY, Jang JS, Shin WG, Kim KH, et al. Initial thrombocytopenia as a simple, valuable predictor for clinical manifestation in acute hepatitis A. Scand J Gastroenterol 2008;43(7)81-8.

11. Black MM, Mann NP. "Gangrenous cholecystitis due to hepatitis A infection"; Journal of Tropical Medicine and Hygiene, vol. 95, N 1, pp. 73-74, 1992.

12. Mourani S, Dobbs SM, Genta RM, Tandon AK, Yoffe B. Hepatitis A virus-associated cholecystitis. Ann Intern Med. 1994;120:398-400. 